\title{
磁小体的生物合成及用于肿瘤靶向 治疗的研究进展
}

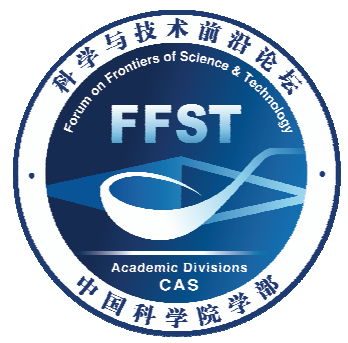

钟林，李晓晨，符军，张友明*，李爱英*

山东大学生命科学学院, 山东大学-亥姆霍兹生物技术研究所, 微生物技术国家重点实验室, 济南, 250100

* 联系人, E-mail: ayli@sdu.edu.cn; zhangyouming@sdu.edu.cn

收稿日期: 2017-03-25; 接受日期: 2017-04-27; 网络版发表日期: 2017-05-12

国家自然科学基金(批准号: 31670097)、科技部国际合作专项(批准号: 2015DFE32850)、山东省重点研发计划(批准号: 2015GSF12101) 和山东省重大专项(批准号: 2015ZDJS04001)

摘要趋磁细菌产生的磁小体是生物膜包被的磁性纳米颗粒, 具有优良的纳米磁特性; 相比化学合成的磁性 纳米材料, 其生物来源赋予磁小体更好的生物相容性和遗传可操作性. 在生物医学领域, 除了用于磁热疗进行 肿瘤治疗外，最近几年其作为靶向药物载体、可能参与肿瘤微环境调控的性质得到研究者的广泛关注; 同时 DNA 重组技术的发展解决了磁小体的产率低而趋磁细菌难培养的问题. 本文综述了磁小体的生物合成及其相关 研究进展, 并对其应用前景进行了展望.

关键词＼cjkstart磁小体, 趋磁细菌, 生物合成, 遗传工程, 肿瘤靶向治疗

趋磁细菌(Magnetotactic bacteria, MTB) 是一大类 能沿着地磁场方向进行趋磁运动的细菌的总称, 不 具有系统分类学上的意义. 这类细菌的特殊性在于 能产生一种原核生物细胞器-磁小体 (magnetosome) (具有 $\mathrm{Fe}_{3} \mathrm{O}_{4}$ 纳米磁核). 这类生物来源的磁纳米结构 不仅纯度高、磁性强、晶型独特、粒度均一, 而且具 有良好的生物相容性及遗传可控性. 当今化学合成 的磁性纳米药物普遍存在易聚集、生物相容性差及制 备工艺复杂等难题; 趋磁细菌合成的磁小体因生物 膜包被而具有更好的生物相容性, 可用于肿瘤靶向 磁热疗和药物载体, 还可能参与肿瘤微环境的免疫 调控. 因其可以生物合成, 具有遗传可控性, 因此磁
小体有可能开发为性能优良的医用纳米磁性材料. 基于基因遗传操作技术的磁小体理性改造或修饰的 成功实践, 使得这种磁性纳米颗粒的潜能愈显昭彰. 人们对磁小体生物合成基因簇的部分或完整获取，对 其合成模块的遗传修饰改造, 对应用表达平台的探索 创新, 必将随着对磁小体代谢调控网络的进一步了解 而迈上新的台阶. 本文重点综述磁小体产生菌、磁小 体的生物合成和改造及其在医药领域的应用.

\section{1 自然界中磁小体的产生菌-趋磁细菌} 趋磁细菌为革兰氏阴性细菌，形态多样，有球

引用格式: 钟林, 李晓晨, 符军, 等. 磁小体的生物合成及用于肿瘤靶向治疗的研究进展. 中国科学: 生命科学, 2017, 47: 572-585 Zhong L, Li X C, Fu J, et al. Biosynthesis and application of magnetosomes in tumor-targeting therapy. Sci Sin Vitae, 2017, 47: 572-585, doi: $10.1360 /$ N052017-00066 
状、杆状、弧形、螺旋状及多细胞聚集等类型; 广泛 存在于水体环境或其沉积物中, 且适应于较为温和 的环境温度、中性 $\mathrm{pH}$ 及微氧或无氧条件, 营养方式 包括化能异养、化能自养或混合营养等多种方式, 极 少数能耐受热泉或极端碱性环境 ${ }^{[1 \sim 6]} .16 \mathrm{~S}$ rDNA 研究 表明, 多数趋磁细菌分属于变形菌门(Proteobacteria) 中的 $\alpha-, \gamma$-或 $\delta$-变形菌纲, 而少数未培养趋磁细菌隶 属于硝化菌门 (Nitrospirae), 还有极少数被列入 Planctomycetes-Verrucomicrobia-Chlamydiae(PVC) 总 细菌门中. 另有一类菌位于暂定分类的 $\mathrm{OP} 3$ 单元 (Omnitrophica), 这意味着趋磁细菌存在进化起源多 样性 ${ }^{[7 \sim 12]}$.

趋磁细菌虽在自然界中数量众多 $\left(10^{7} \sim 10^{9}\right.$ 个 $\left.\left(\mathrm{cm}^{3}\right)\right)$, 但因其营养要求复杂, 生存条件苛刻, 难于 纯化培养. 目前为止, 只有几株典型菌株得到纯培养 并被广泛研究, 如 $\alpha$-变形菌门中的 Magnetospirillum magneticum 菌 株 AMB-1, Magnetospirillum gryphiswaldense MSR-1, Magnetospirillum magnetotacticum MS-1 以及 Magnetococcus marinus MC-1, 还有分属于 $\delta$-变形菌门及 $\gamma$-变形菌门中的细 菌 Desulfovibrio magneticus RS-1, BW-1 和 BW- $2^{[7,13,14]}$.

趋磁细菌因可借助胞内磁小体链在地磁场中运 动而得名 ${ }^{[15 ~ 20]}$. 关于趋磁细菌在地磁场中的运动, 最初的研究者用简单的 “趋磁模型” 来描述它们的行 为(认为趋磁细菌朝着与地球磁场线或平行或反向平 行的方向泳动, 不受局部磁场方向影响 $)^{[21]}$, 后以趋 磁螺旋菌 MS-1(Aquaspirillum magnetotacticum) 为例, 发展出更为复杂的“趋磁-趋氧模型 (magnetoaerotaxis) "[21-23], 并由此将趋磁细菌分为两种类型, 即极向趋磁细菌 (polar MTB) 和轴向趋磁细菌 (axial MTB); 对于前者, 地磁场提供了其运动的轴轨与方 向, 迁移方向恒定, 无周期性逆转, 其局部泳动方向 的逆转及逆转速度取决于在此过程中对局部氧气浓 度及磁场方向的感应; 对于后者, 其迁移方向不定, 伴有周期性的方向逆转, 逆转的速度取决于对局部氧 气浓度及浓度梯度的感应 ${ }^{[22,24]}$. 除此之外, 随着实验 数据的大量整合和理论研究的深入, 人们所发现的趋 磁细菌的趋磁行为愈趋复杂多样, 单一的趋磁-趋氧 模型已经难以很好地解释这些行为. 研究者提出了 单极趋磁细菌趋磁行为 (unipolar MTB)(以区别于轴 向和极向趋磁)、趋光模型、趋化模型等作为补充 ${ }^{[24]}$.
综上所述, 趋磁细菌具有多样性, 如形态多样、 生理多样性、系统发育多样、营养类型多样及趋磁行 为多样性等. 然而绝大多数趋磁细菌难以进行纯化 培养, 再加上相关技术手段贵乏, 由这些天然趋磁细 菌为出发点展开对磁小体性质与应用的研究受到了 很大限制。

\section{2 磁小体的结构}

趋磁细菌体内积累的磁小体是由双层磷脂膜包 被的 $\mathrm{Fe}_{3} \mathrm{O}_{4}$ (少数为 $\mathrm{Fe}_{3} \mathrm{~S}_{4}$ ) 纳米晶体颗粒.

\section{1 磁小体膜的主要组分}

包括糖脂、硫脂及磷脂等, 都与细胞质膜成分类 似, 一般认为磁小体膜由细胞质膜内陷而来 ${ }^{[25,26]}$.

\section{2 磁小体膜上的特异的蛋白成分}

如 Mam 蛋白(magnetosome membrane)或 Mms 蛋 白(magnetic particle membrane specific), 其与质膜、 外膜、周质等区域差异明显 ${ }^{[26,27]}$.

磁小体膜在胞内形成了一个独特而复杂的区间 结构, 其上膜蛋白的精密互作为磁小体的尺寸、形 貌、组分的形成创造了良好的物质基础, 是导致磁小 体呈现菌种特异性的重要因素. 此外, 磁小体膜也为 磁小体的生物矿化提供了良好的生物化学环境; 同时, 它将磁小体区域与其他细胞区间分隔开, 有助 于细胞免除磁小体生物矿化过程中副产物的潜在毒 害 $^{[25,28 \sim 31]}$.

\section{3 磁小体的磁核}

单个磁纳米颗粒的直径一般分布在单磁畴磁晶 体范围(35 100 nm), 以 $\mathrm{Fe}_{3} \mathrm{O}_{4}$ 居多, 有时会有 $\mathrm{Fe}_{3} \mathrm{~S}_{4}$ 以及一些微量的过渡金属元素的掺入. 其晶型多样, 有立方八面体形、长菱形和子弹头等形式, 呈单链或 多链或分散排布于膜内 ${ }^{[32]}$.

趋磁细菌合成磁小体可能具有几方面的进化优 势, 以助其在自然界中占据最优的生态位, 如储存能 量(间接甚至直接参与电子传递过程)、细胞排毒(免除 呼吸作用中氧自由基或游离铁离子的毒害)、趋氧-趋 磁联合作用等. 但磁小体的存在对于某些趋磁细菌 来讲也可能是一种能量负担, 所以有时会产生自发 丢失的现象 ${ }^{[21,33,34]}$. 生物合成的磁晶体不仅化学纯度 
高, 而且其粒径分布、形状、晶型等皆存在菌种特异 性, 如磁螺菌属(Magnetospirillum genus) 细菌一般只 矿化由 $\mathrm{Fe}_{3} \mathrm{O}_{4}$ 构成的立方八面体结构的磁小体单链. 这意味着磁晶体生物矿化过程中, 存在严格的调控 机制.

\section{3 磁小体的生物合成}

无论是可培养还是未培养的趋磁细菌, 绝大多 数的基因组上都含有一个典型且复杂的参与磁小体 生物合成的基因岛(称为“磁小体岛”), 可达 $100 \mathrm{~kb}$, 能编码 40 多个蛋白; 此处的碱基序列不仅 GC 含量 异乎寻常, 而且存在丰富的 tRNA 基因、假基因、整 合酶、转座酶及转座子等序列 ${ }^{[35 \sim 37]}$, 这些元素在基因 组上一定部位的簇集形成了特定的基因岛 (大基因 簇 $)^{[38,39]}$. 作为水平基因转移的标志之一, 磁小体岛 的存在一定程度上可以解释趋磁细菌的系统分类多 样性 ${ }^{[40 \sim 42]}$

磁小体岛上的多数基因以操纵子形式存在, 目 前所有已鉴定的趋磁细菌都存在操纵子 $\operatorname{mam} A B$, 其
在磁小体生物合成过程中发挥关键作用。由于未培 养趋磁细菌中的相关研究及机制推断依然贵乏，本 文主要介绍研究得较为透彻的可培养细菌 Magnetospirillum magneticum(AMB), 其磁小岛包括 mamAB, mamGFDC, mamXY, mms6 及 $f e o A B 1$ 五个操 纵子内的 30 多个基因(图 1A).

磁小体生物合成过程主要包括：质膜内陷引发 磁小体膜的形成、铁的吸收及转运及磁核的矿化及成 熟、磁小体链的有序组装. 这一系列过程受到磁小体 岛编码蛋白的精密调控 ${ }^{[43]}$.

磁小体合成相关蛋白在不同趋磁细菌中具有多 样性, 除了普遍存在于所有趋磁细菌中的特定功能 性蛋白(作用于磁小体形成的 4 个主要阶段)外, 其余 相关蛋白如决定磁小体特殊形状、特殊组分的蛋白则 仅存在于特异的趋磁细菌中 ${ }^{[8,44 \sim 52]}$. 此外, 长期以来 人们认为趋磁细菌只能控制合成一种磁小体 ${ }^{[52]}$, 直 到 2010 年, 研究人员分离到一株罕见的趋磁细菌, 发现它有两套基因岛，分别控制 $\mathrm{Fe}_{3} \mathrm{~S}_{4}$ 和 $\mathrm{Fe}_{3} \mathrm{O}_{4}$ 两种 不同的磁小体生成 ${ }^{[51]}$.

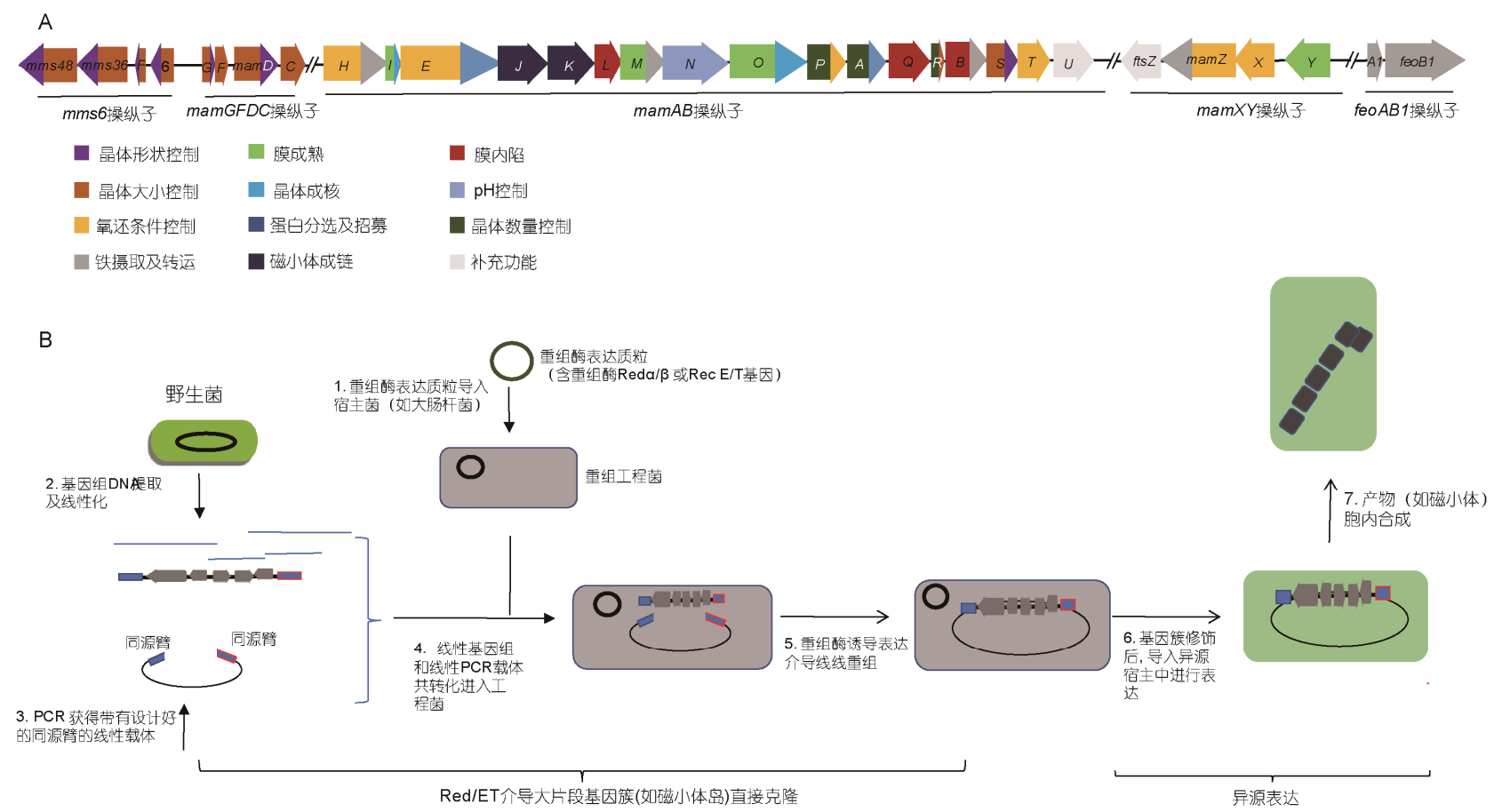

图 1 趋磁细菌 AMB 中磁小体岛(基因簇)的结构以及磁小体岛的直接克隆和异源表达流程

$\mathrm{A}$ : 磁小体合成基因根据功能大致划分为 12 类，包含在五大操纵子内，但磁小体基因岛中同一基因往往发挥多种功能，不同基因间的功能也 普遍交叉, 所以基因功能的分类还有待完善; B: 利用 Red/ET DNA 重组技术从不可培养的趋磁细菌中直接克隆磁小体岛(大基因簇)并进行异 源表达 


\section{1 磁小体膜形成}

此阶段主要包括质膜蛋白的招募储存、细胞质膜 的内陷及磁小体膜(腔体)的形成. 已观察到在 AMB 细菌中磁小体膜内陷随意发生在质膜的多个位置, 同时形成的磁小体囊膜以连续体的形式存在; 而在 MSR 菌中几乎所有的囊膜都独立存在. 这是否意味 着磁小体膜具有两种形成方式, 亦或还有其他方式 都尚未有定论.

磁小体膜的内陷过程可以随机而迅速地发生在 细胞质膜某些区域. 除了某些核心蛋白(如 MamB 蛋 白负责内陷的起始, 其定位于质膜上进行相关蛋白 的招募)外, 其它相关蛋白可能主要发挥膜弯曲或分 子支架作用, 用以形成陷窝或维持膜结构, 包括 MamM, MamL, MamI, MamQ, MamY 以及 mamAB, $m a m G F D C, m m s 6$ 操纵子中的相关蛋白. 它们通过蛋 白分子间的相互作用诱导质膜内陷, 且在此过程中 单独的蛋白缺失对内陷过程没有明显影响, 这可能 和蛋白间的功能互补有关. 需要指出的是, 相关蛋白 如 MamM, MamL, MamI, MamQ 还可能在晶体矿化 和磁小体膜的成熟过程中发挥作用 ${ }^{[25]}$.

MamE 可能也参与磁小体膜的形成, 它拥有用 于自我组装的 TPR(tetratricopeptide repeat)基序, 在 蛋白的膜定位过程中发挥重要作用 ${ }^{[53]}$, 其以某种特 定机制定位于囊膜, 并进行自我组装, 随即, 引发多 种可相互作用蛋白的相对定位, 如 MamC, MamF, MamI 等定位于质膜, MamA 定位于囊膜, 随之 MamA 进行功能蛋白招募, 并进一步引发蛋白间的 相互作用及定位, 激活下一步磁小体的生物矿化过 程 ${ }^{[43,54]}$.

\section{2 磁小体的生物矿化(铁的吸收转运及磁核的矿 化及成熟)}

此过程包括：铁的运载与吸收、氧化还原条件的 控制、晶体的成核、表型、大小及数量调控.

(1) 铁的运载与吸收. 趋磁细菌特异的铁运载 系统在此过程中发挥主导作用, 如 AMB 菌中, 由蛋 白 $\mathrm{MamB}$ (属于 cation diffusion facilitator family CDF 家族中的亚族 $-\mathrm{Fe} / \mathrm{Zn}$ 转运亚族), MamM, MamH(major facilitator superfamily 家族中的 MFS 亚 族) 以及 MamZ 构成了磁小体特异的铁运载系统 [55 58]. 其中, MamB 和 $\mathrm{MamM}$ 负责亚铁离子的运输,
部分功能互补的 $\mathrm{MamH}$ 和 $\mathrm{MamZ}$ 则负责铁离子运 载 ${ }^{[28,59 ~ 63]}$. 在 MSR 菌中, 来自周质空间的铁成分经 由细胞一般性运载系统(如 GTP 依赖性 $\mathrm{Fe}^{2+}$ 运载蛋白 FeoB1 和 FeoB2)载入胞质后, 或与有机成分结合, 以 结合铁形式输往磁小体膜腔, 或以游离铁形式 $\left(\mathrm{Fe}^{2+}\right.$ 及 $\left.\mathrm{Fe}^{3+}\right)$, 在特异运载蛋白 $\mathrm{MamB}$ 与 $\mathrm{MamM}$ 及 $\mathrm{MamH}$ 与 $\mathrm{MamZ}$ 作用下载入磁小体腔, 并由此逐渐累积铁 成分(形成铁池).

(2) 进入磁小体腔的铁成分经历氧化还原. 前 述铁转运蛋白 MamZ(属于 YedZ 铁还原酶类似蛋白) 在参与铁转运的过程中可能还同时控制着铁的还 原 ${ }^{[64]}$. 而 MamP, MamT, MamX 及上述 MamE 蛋白或 可形成酸性口袋用以结合和氧化铁成分 ${ }^{[65]}$ ，这些蛋 白积极的氧化还原作用有效地均衡了膜腔内的 $\mathrm{Fe}^{2+} / \mathrm{Fe}^{3+}$ 比率, 用以满足混合价态的 $\mathrm{Fe}_{3} \mathrm{O}_{4}$ 磁晶体合 成所需; 与此同时, 细胞将腔内生理生化条件控制在 最适水准(如局部 $\mathrm{pH}$ 大于 7、低氧还电位等)，随即相 关蛋白引导 $\mathrm{Fe}^{2+} / \mathrm{Fe}^{3+}$ 成核及晶体生长、并控制晶型、 大小、数量和纯度. 虽然研究发现这些蛋白均含有 2 3 个特异性的血红素结合基序 $\mathrm{CxxCH}$ (cysteine$\mathrm{X}$-X-cysteine-histidine), 但在功能上, 此基序是否存 在与矿化晶体的形成无绝对的关联 ${ }^{[64,66 \sim 70]}$.

（3）晶体的成核、表型、大小及数量调控. 推测 或通过可溶性 $\mathrm{Fe}^{2+}$ 和 $\mathrm{Fe}^{3+}$ 共沉淀而直接形成磁核, 或 先形成前体矿物相的形式, 然后逐渐向磁晶体形式 过渡(迄今为止 $\mathrm{Fe}_{3} \mathrm{O}_{4}$ 晶体尚未发现过有前体存在, $\mathrm{Fe}_{3} \mathrm{~S}_{4}$ 则发现有前体). 对 AMB 及 MSR 菌的突变实验 证明, 蛋白 MamE, MamM 和 MamO 是必需蛋白, 均 涉及成核作用 ${ }^{[56,66,69,71,72]}$; 而 Mms5, Mms6, MamC 和 $\mathrm{MamD}$ 可能仅参与后续的晶型和大小控制 ${ }^{[47,71,73,74]}$. 在晶体成核过程中，这些蛋白之间可能通过协同作 用来控制晶体生长及停转; 以蛋白分子 (MamD)为模 板，控制晶格-原子排布的空间构架; 磁晶体结合蛋 白(Mms5, Mms6 和 MamD)则通过与晶面相互作用而 控制或稳定晶体生长 ${ }^{[75,76]}$. 另外, $\mathrm{MamN}$ 作为 $\mathrm{H}^{+}$离子 泵转运蛋白, 可将晶体生长过程中释放的质子泵出, 稳定磁小体膜腔内 $\mathrm{pH}^{[16,69]}$. 除此之外，几个基因 (mamS, mamR, mamN, mamF, mms5, mms6, mamD, $m m s F, m m s 36, m m s 48, m a m A$ 和 $m a m P$ )或与磁晶体大 小和晶体数量控制有关 ${ }^{[47]}$. 磁小体颗粒数量因菌株 不同而有所差异，在趋磁螺菌中，磁小体颗粒可多达 100 个. 


\section{3 磁小体链的有序组装}

多个磁小体颗粒为降低其内生性的静磁能而倾 向于呈现聚集态或环状. 在趋磁细菌中, 由单个磁小 体组装而成的链状形式可获得最佳的磁力效应, 这 种高度有序的磁小体链需要依赖蛋白作用来稳定磁 小体, 并介导链状结构与 MTB 细胞相互关联, 协同 作用. 因此, 磁小体链的组装是被动的磁力驱动与积 极的蛋白调控双重作用的结果 ${ }^{[77]}$.

在 MSR 和 AMB 中, MamK(肌动蛋白样蛋白)和 $\mathrm{MamJ}$ 是参与磁小体链组装至关重要的蛋白质. 在此 过程中, MamK 自我组装为一种特殊的长丝状结构, 类似于细胞的微丝结构, 可与多个磁小体结合, 并由 此形成骨架微丝依赖的磁小体链状形式. 人们推测 MamK 以一种类似于 “肌动蛋白踏车行为” 的方式驱 动短链磁小体协作运动, 定位于细胞中端(MSR), 随 即在相关蛋白作用下组装成成熟的长链结构. 所以 MamK 主要在短链磁小体组装成长链及定位过程中 发挥作用. 而 MamJ 则充当磁小体与 MamK 微丝结构 的连接体, 介导磁小体膜与 $\mathrm{MamK}$ 的连接 ${ }^{[78 \sim 80]}$.

MamK 和 MamJ 及其同源蛋白(如类 MamK 蛋 白、 $\operatorname{limJ}$ 蛋白)等在 MSR 和 AMB 中共同发挥作用, 有 序组装磁小体链, 驱动磁链定位于特殊细胞位置或 形成特殊的链状结构(如 AMB 中, 成熟囊泡与空囊泡 夹杂组装). 然而迄今为止, 人们对磁小体链组装过 程中的某些关键的分子机制依然缺乏了解, 如短链 的形成机制、MamJ 非保守的替代机制(其只发现存在 于趋磁螺菌中)及 Mamk 的普遍性作用机制等, 有待 进一步阐释 ${ }^{[11,82]}$.

\section{4 磁小体生物合成途径的重构和遗传改造}

化学合成磁纳米颗粒普遍存在反应温度极端、反 应条件难以控制、有毒试剂使用、后修饰复杂费力等 问题, 同时其均匀度、结晶度、纯度、粒径分布、晶 型控制及可操作性都远远不及生物合成的磁小体. 然而, 自然界中绝大多数的趋磁细菌都属于难以培 养的微生物. 即便经过 30 多年的努力, 人们也只获 得了屈指可数的几株趋磁细菌的纯培养 ${ }^{[27,83]}$, 其磁 小体产量令人沮丧 ${ }^{[84]}$, 而磁小体晶体尺寸、形貌和组 分的失控等问题也让人束手无策, 这些都极大限制 了磁小体的大规模应用.
近年来迅速发展的遗传操作手段(如 Red/ET DNA 重组技术)有望用于控制或提高磁小体的产量、 纯度、大小、晶型乃至磁小体链状结构, 克服传统优 化培养的瓶颈缺陷. 结合 DNA 转入技术(如接合转 移、转化、电转化)及蛋白标记技术(荧光素酶、绿色 苂光蛋白)等或可加速对磁小体合成机制及大规模生 产应用的研究。

\section{1 利用 Red/ET 同源重组技术实现磁小体的异源 生长和产量的提高}

Red/ET DNA 重组技术(也叫 DNA 重组工程、重 组遗传工程)是依托 $\lambda$ 或 Rac 噬菌体的内源性 DNA 重 组蛋白 $(\operatorname{Red} \alpha / \beta$ 及 $\operatorname{RecE} / \mathrm{T})$ 而建立起来的一套完善的 基因重组技术体系. 与现行的 DNA 重组系统(如 Gibson 组装、酿酒酵母重组体系、酶切连接等)相比, 其优势在于不涉及大片段的 PCR 或 DNA 合成、无需 长的同源片段、无需严格的限制酶切位点、省时省力 且高效快捷. 这些优点使得其在基因的敲除、敲入、 修饰、克隆、亚克隆、组装等遗传操作方面迅速得到 应用和发展, 并逐渐完善成为一种行之有效的重组 工程技术; 而其在大片段基因簇方面的有效应用，如 Red/ET 直接克隆技术 ${ }^{[55,86]}$, 不仅可以实现大片段、高 重复的基因簇(如次生代谢基因簇一般 $50 \mathrm{~kb}$ 以上)的 载体化、工程化连接, 而且可与来源基因组进行无缝 对接, 直接从基因组上获取目的基因, 避免了因繁杂 PCR 或其他 DNA 合成技术而导致的相关突变, 具有 极高的保真性.

$\operatorname{Red} / \mathrm{ET}$ 技术主要利用 RecE 或 Red $\alpha$ 蛋白的 $5^{\prime} \rightarrow$ $3^{\prime}$ 端外切酶活性, 及 RecT 或 Red $\beta$ 单链结合蛋白的退 火和链侵入特性, 在造成具有同源臂(一般在 15 80 $\mathrm{bp})$ 的双链目的 DNA 的单链悬突后，以 $\operatorname{RecT}$ 或 $\operatorname{Red} \beta$ 单链结合蛋白为引导, 将同源臂的单链悬突部分与 受体分子的同源臂部分特异结合，并由此导致了供 体与受体 DNA 分子的重组与替换(图 1B). 因此, $\mathrm{Red} / \mathrm{ET}$ 重组技术成为趋磁细菌遗传操作中为数不多 的有效的规模化、成熟化的操作手段之一.

张友明课题组和德国课题组合作，利用 Red/ET 同源重组技术, 对生长缓慢的趋磁细菌 Magnetospirillum gryphiswaldense 的大片段磁小体岛 基因进行了直接克隆和异源表达，分 3 步将 4 个操纵 子共计 29 个基因依次克隆，并构建成转座质粒，以 转座方式转入异源宿主细胞(生长迅速的光合作用模 
式菌株-深红红螺菌 Rhodospirillum rubrum)中: 在单 独转入主要调控操纵子 $\operatorname{mam} A B$ 未产生矿化反应后, 又相继转入了 $m a m G F D C$ 及 $m m s 6$ 操纵子, 在此过程 中, 发现胞内含铁量与野生型相比增加了 2.4 倍, 并 伴有不规则的高电子密度颗粒生成, 但依然未检测 到磁力反应, 直至转入 $\operatorname{mam} X Y$ 及其附属基因 $f t s Z m$, 形成 29 个基因 $(26 \mathrm{~kb}$ )的“四操纵子联合调控”表达盒. 此时, 深红红螺菌获得了较强的磁力反应, 检测到磁 小体链的成功生成, 说明利用 Red/ET 同源重组技术 使深红红螺菌具备了磁小体合成能力, 且在晶体尺 寸、形貌和组分上都与原趋磁细菌中分离的磁小体一 致. 这使得磁小体的生产变得更为高效、实用 ${ }^{[87]}$.

该研究使得磁性纳米结构在具备工业应用价值 的宿主中高效生产成为可能, 有力推进了利用合成 生物学技术对不同生物进行内源性磁化的研究. 在 实际应用中, 可人为控制其基因表达, 从而实现宿主 细胞有磁、无磁状态的转换, 进而在大规模工业生产 中, 利用磁场实现工程菌的高效分离. 这一基础性研 究为人工合成磁性纳米粒子及其他含铁化合物提供 了新的技术路线.

进一步通过对 M. gryphiswaldense 菌株染色体改 造后发现, 单个操纵子的加倍整合, 如 $m m s 6$ 的整合 菌株(2 4 倍倍增)中, 随着倍数的增加, 磁晶体大小 及数量也持续增加 $(70 \%)$, 直至五倍倍增时出现缩减. $m a m X Y, m m s 6, m a m G F D C$ 和 $m a m A B$ 的单独或联合加 倍均能导致磁小体的数量、晶体大小乃至磁小体链的 增加. 与原生态的菌株相比, 其四操纵子联合的倍增 菌株中, 磁小体产量出现了 2.3 倍增量 ${ }^{[88]}$. 这意味着 利用 Red/ET DNA 同源重组技术在基因表达水平进 行人工调控, 实现对磁小体的相关特性的“量身定 做”是可能的.

或许未来随着对磁小体调控网络理解的深入以 及相关操作技术的进步, 人们可以精确的对某个磁 小体岛关联基因进行操作，如过表达、敲除、敲降、 敲入等, 不仅能实现原生态磁小体“生物生产工厂” 的构建, 而且可以满足应用所需, 合成具有特殊功能 和特性的磁小体.

\section{2 利用融合蛋白技术进行磁小体的表面修饰}

磁小体的双分子层膜性结构中含有许多功能化 的表面蛋白(如前述在膜结构中占绝大多数的多种参 与膜合成或后续发挥作用的蛋白), 因此可在分子水
平上操作磁小体膜性结构, 构建融合蛋白, 用于磁小 体相关蛋白的作用机制及载药的研究.

(1) 融合蛋白为标志的展示及标记技术. 将茧 火虫苂光素酶基因 $l u c$ 与磁小体膜基因 $m a g A$ 融合表 达, 成功获得了融合表达子; $\mathrm{GFP}$ 与 $\mathrm{MamC}, \mathrm{MamF}$ 和 MamG 构建融合蛋白, 并调和趋磁细菌生长、磁小体 生物矿化及 GFP 苂光强度之间的矛盾, 取得了最优 表达 ${ }^{[89]}$; 而通过组成型的 $\mathrm{P}_{\mathrm{mamDC}}$ 或诱导型 $\mathrm{P}_{\mathrm{tet}}$ 启动子 表达密码子优化的 EGFP 与 MamC 融合蛋白, 获得了 高度表达的苂光标记蛋白 ${ }^{[00]}$.

(2) 固定技术. 黄杆菌 (Flavobacterium sp.)ATCC27551 中的 opd 基因(编码对氧磷酸水解酶, 在水解农药污染物及神经毒素方面发挥作用)可与 $m a m C$ 基因融合表达, 并由此得到了具有磷酸水解酶 活性的磁小体颗粒. 与纯酶相比, 其活性和稳定性良 好, 并且来源稳定, 分离方便, 可重复利用 ${ }^{[91]}$; 利用 M. magneticum AMB-1 中表达量最丰富的磁小体相 关蛋白 $\mathrm{Mms} 16$ 与 $\mathrm{G}$ 蛋白偶联受体结合 (后者作为生物 体信号网络中至关重要的受体之一, 在生物调控过 程中发挥重要的作用, 因此是许多疾病治疗的潜在 靶标), 二者的融合表达不仅能获得具有优良特性的 受体蛋白，而且易于分离纯化和重复利用 ${ }^{[92]}$.

（3）分离技术. 如以蛋白 $\mathrm{A}$ 基因与磁小体膜蛋 白相关基因的融合表达为基础，建立细胞分离分选 (如从血液样品中分离细胞)技术、利用抗体抗原融合 表达分离样品病原菌.

（4）检测技术. 磁小体膜蛋白与抗体融合用于 疾病指标诊断、与生物素或亲和素偶联用于癌细胞的 检测. 除此之外，生物素融合体系还在大分子检测、 固定和回收中发挥作用 ${ }^{[03 ~ 97]}$, 生物活性物质融合表 达用于免疫分析 ${ }^{[98,99]}$ 等.

\section{5 磁小体的体外仿生}

仿照生理条件在体外控制合成磁纳米晶体, 即 仿生合成, 也是区别于无机化学合成的有利途径之 一. 利用功能性及结构性的磁小体蛋白与其他自我

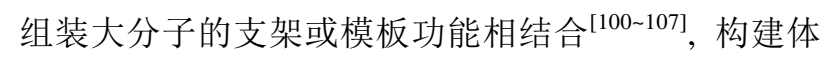
外生物反应器, 不仅能实现金属离子的矿化, 而且磁 纳米晶体的粒径分布、形状、组织形式都能通过调控 满足所需. 在此过程中, 逐步逐级的成核作用、晶体 的生长、晶核成分、链组装等的控制尤为重要. 
在趋磁细菌合成磁小体的过程中, $\mathrm{Fe}_{3} \mathrm{O}_{4}$ 晶体的 合成一般没有前体相, 而在体外仿生合成时, 无定 形前体相的形成对于晶体生长的表型及形状意义重

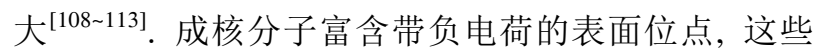
位点通过静电相互作用结合阳离子或阳离子复合物; 随着前体的形成，位点间的差异及相互作用凸显出 来, 并由此影响前体相和晶格结构; 前体相持续生 长, 晶种出现, 随之持续长大 ${ }^{[114,115]}$, 并在相关生物 大分子作用下稳定、成熟 ${ }^{[115,116]}$.

此时, 通过离子扩散速率和微环境的调节, 如使 用凝胶或多孔介质控制晶体生长速度, 或人工构建

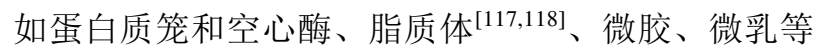
类似于磁小体囊膜的结构 ${ }^{[106,119,120]}$, 以囊泡体积大小 限制晶体的形状及大小. 此外, 不同金属成分的添加 及条件控制, 可以对纳米晶体的组分进行调节 ${ }^{[27]}$.

值得一提的是, 在磁晶体中掺入其他元素对磁 晶体进行改性已有相关文献报导 ${ }^{[121]}$. 如李金华等 人 $^{[122]}$ 在向 AMB-1 的培养基中加入钴元素, 并最终获 得了具有较高矫顽力的改性磁小体, 其立方八面体 晶格中部分的 $\mathrm{Fe}^{2+}$ 被 $\mathrm{Co}^{+}$所取代.

\section{6 磁小体在肿瘤诊断和治疗中的应用}

综合前述, 磁小体这类特殊细胞器的形成得益 于趋磁细菌的精密调控, 其无机核心依托于膜性结 构, 二者相辅相成, 赋予其稳定的单磁畴、分布紧窄 的粒径、独特均一的晶型、高的化学纯度、优良的单 分散性能、荷负电及功能化的表面结构、高的生物相 容性及遗传可操作等特性, 并因此不断推动着磁小 体在各方面的广泛应用, 尤其是在医药领域的应用 一直是人们关注的焦点.

\section{1 磁小体用于磁热疗及调控肿瘤微环境}

肿瘤细胞与正常组织细胞相比耐热性较低, 其 耐受温度一般在 $42^{\circ} \mathrm{C}$ 以下. 而磁小体的弛豫损耗赋 予了其在交变磁场中产热的特性. 与化学合成的磁 纳米颗粒相比, 生物合成的磁小体驰豫或磁滞能量 损失较高, 并因此产生更多的热量. 其晶体稳定, 生 物相容性和遗传可操作性高, 在组织中成链或成环, 不易团聚, 在目标靶位可协同作用, 可以持续对癌症 细胞造成强力杀伤, 而不损害正常组织细胞. 因此, 磁小体或可发展为一种新型的磁热疗手段用于癌症
治疗. 为此, 相关领域的研究者对其磁特性, 如矫顽 力、各向异性常数、生物组织分布、代谢途径、产热 量、生物相容性等进行了探究.

磁热疗除了可以热裂解肿瘤细胞导致其死亡外, 也可能与肿瘤微环境的免疫调控有关. 最近, 关于肿 瘤细胞受热裂解激发机体免疫效应的研究引起人们 关注. 研究者将纳米颗粒与免疫佐剂结合, 靶向导入 肿瘤. 具有光诱导产热的纳米颗粒在远红外光照射 下可通过热疗清除癌症细胞. 在此过程中, 癌症细胞 的裂解会产生大量的癌症相关抗原, 引发多重获得 性免疫反应; 若此时辅以检查点抑制剂(抑制 $\mathrm{T}$ 细胞 共抑制分子及其相关配体, 刺激 $\mathrm{T}$ 细胞反应) 以对抗 癌症细胞对 $\mathrm{T}$ 细胞的抑制作用, 可极大的刺激抗癌免 疫反应. 这种抗癌策略长时、高效而且生物相容性高, 适用范围广. 尽管此项研究是基于光热疗纳米颗粒 的应用, 亦同样有助于阐释癌症的磁热疗机制, 对磁 小体磁热疗的相关临床研究具有极大借鉴作用 ${ }^{[123]}$.

\section{2 磁小体用于肿瘤诊断的核磁共振成像}

基于磁性纳米颗粒能增大质子共振吸收的特性, 可作为高效对比剂而应用于核磁共振成像 ${ }^{[124]}$, Faivre 等人 ${ }^{[16]}$ 已利用苂光染料耦合的磁小体同时用于核磁 共振成像和近红外苂光成像, 获得了较为理想的 结果.

磁小体蛋白作为报告基因可用于报告基因成像. 现行的影像报告基因的成像关键在于报告基因对对 比剂的协助作用, 而磁小体合成相关基因中有多种 分属于各类铁成分摄取或转运相关的基因, 因此其 可作为一种良性的报告基因, 在靶向细胞中表达, 从 而获得胞内的 MRI 高分辨率影像. 这种非侵入性的 成像技术不仅有助于实时示踪和监测癌症细胞动态, 而且其生物相容性好, 信号强度高, 能同时获得解剖 和生理信息, 在临床应用上极具价值 ${ }^{[125]}$.

\section{3 磁小体/趋磁细菌用于肿瘤靶向药物输送}

磁小体膜表面具有丰富氨基、羧基、嵌合的蛋白 质、游离脂肪酸、糖类和磷脂等生物分子或基团, 尤 其适宜于药物载体系统的构建, 如使用成熟的化学 交联方法, 通过多种交联剂/大分子桥梁的偶联反应 或化学修饰作用, 将各类分子配体如生物素/亲和素、 多种药物、抗体、酶类、激素、核酸等负载于磁小体 表面, 用于抗菌抗癌活性的研究 ${ }^{[126 ~ 135] . ~}$ 
当前, 随着靶向治疗的兴起, 磁小体及其产生菌 日益成为靶向治疗研究的焦点之一. 因为缺乏特殊 的驱动力, 现行或研究的药物载体对于肿瘤深处缺 氧部位的靶向效果不佳. 为了获得更大的药物载量、 更高的药物稳定性及保留时间, 可在外加磁场的引 导下利用磁小体载药到达肿瘤部位.

值得指出的是, 肿瘤增殖区域中肿瘤细胞的大 量增殖导致了肿瘤组织氧气的贵乏, 这尤其适于趋 磁细菌的厌氧生长; 在趋磁细菌表面共价结合脂质 体包埋的药物颗粒, 可通过磁场感应和低氧感应靶 向定位于常规纳米级载体难以企及的肿瘤缺氧区域, 从而有效提升了纳米级载体在肿瘤靶向治疗领域的 应用价值 ${ }^{[136]}$.

\section{7 展望}

随着对趋磁细菌及磁小体生物合成调控网络的 逐步阐明, 分子操作技术的日渐成熟, 从分子水平上 对趋磁细菌及磁小体进行精准操作, “量体裁衣”式地 设计磁纳米工具将成为可能. 这类极具潜力的纳米 工具将为未来精准医疗的发展添砖加瓦, 并在应用 过程中不断完善和成熟. 此外, 集磁学、矿物学、生 物学于一体的特性也将极大促进其获得新的突破和 发展。

在肿瘤靶向治疗方面, 一些最新进展无疑将为 磁小体应用于抗肿瘤治疗提供更好的研究思路或支
持. 磁小体的磁核是 $\mathrm{Fe}_{3} \mathrm{O}_{4}$, 而最近有研究者发现一 种 $\mathrm{Fe}_{3} \mathrm{O}_{4}$ 纳米磁性颗粒本身也具有抑制肿瘤的效果, 它能激活肿瘤抑制的促炎性 M1 巨噬细胞的招募, 促 进功能极化, 并由此而引发相关细胞调亡途径, 如细 胞调亡途径中的主要终末剪切酶 caspase-3 以及 TNF- $\alpha$ 和 IL-10 等细胞因子的增加更加速了癌症细胞 的死亡 ${ }^{[137]}$. 所以, 在当今对肿瘤微环境的调控成为 研究热点的情况下, 磁小体本身以及磁产热用于肿 瘤靶向治疗或将成为新的关注焦点.

不久前, 研究人员发展了一种新型的药物运载 与释放一体化的投递体系, 将为磁小体和趋磁细菌 用作靶向药物载体提供更坚实的支持 ${ }^{[138]}$. 利用无毒 化的肿瘤靶向性定殖细菌携带抗癌药物导入小鼠肿 瘤组织中, 在分子开关作用下, 在肿瘤原位实现药物 的合成及释放. 若能把磁小体岛导入庆氧或微好氧 的靶向定殖细菌中, 一方面可有力增加对肿瘤的靶 向性; 另一方面, 除磁小体可通过热疗或免疫调控来 实现原位肿瘤治疗以外, 无毒害的肿瘤靶向定殖菌 本身具有对肿瘤微环境的免疫调控作用 ${ }^{[139]}$; 此时若 再结合化疗药物的原位表达, 则可建立一种多联靶 向治疗的新策略, 实现磁小体肿瘤靶向治疗技术上 的关键突破.

此外, 最近发展的光热效应 ${ }^{[140]}$ 联合免疫佐剂、 肿瘤疫苗、免疫检验点抑制剂等的疗法 ${ }^{[123]}$, 或可与 磁热疗法及磁小体靶向载体实现无缝结合, 磁小体 的应用将会得到进一步扩大.

\section{参考文献}

1 Abreu F, Carolina A, Araujo V, et al. Culture-independent characterization of novel psychrophilic magnetotactic cocci from Antarctic marine sediments. Environ Microbiol, 2016, 18: 4426-4441

2 Revathy T, Jacob J J, Jayasri M A, et al. Isolation and characterization of Magnetospirillum from saline lagoon. World J Microbiol Biotechnol, 2016, 32: 109

3 Chen Y R, Zhang W Y, Zhou K, et al. Novel species and expanded distribution of ellipsoidal multicellular magnetotactic prokaryotes. Environ Microbiol Rep, 2016, 8: 218-226

4 Lefevre C T, Abreu F, Schmidt M L, et al. Moderately thermophilic magnetotactic bacteria from hot springs in Nevada. Appl Environ Microbiol, 2010, 76: 3740-3743

5 Bazylinski D A, Frankel R B. Magnetosome formation in prokaryotes. Nat Rev Microbiol, 2004, 2: 217-230

6 Abreu F, Morillo V, Nascimento F F, et al. Deciphering unusual uncultured magnetotactic multicellular prokaryotes through genomics. ISME J, 2014, 8: 1055-1068

7 Lefevre C T, Viloria N, Schmidt M L, et al. Novel magnetite-producing magnetotactic bacteria belonging to the Gammaproteobacteria. ISME J, 2012, 6: 440-450

8 Lefevre C T, Trubitsyn D, Abreu F, et al. Comparative genomic analysis of magnetotactic bacteria from the Deltaproteobacteria provides 
new insights into magnetite and greigite magnetosome genes required for magnetotaxis. Environ Microbiol, 2013, 15: 2712-2735

9 Lin W, Li J, Pan Y. Newly isolated but uncultivated magnetotactic bacterium of the phylum Nitrospirae from Beijing, China. Appl Environ Microbiol, 2012, 78: 668-675

10 Deng A, Lin W, Shi N, et al. In vitro assembly of the bacterial actin protein MamK from 'Candidatus Magnetobacterium casensis' in the phylum Nitrospirae. Protein Cell, 2016, 7: 267-280

11 Li J, Menguy N, Gatel C, et al. Crystal growth of bullet-shaped magnetite in magnetotactic bacteria of the Nitrospirae phylum. J Royal Soc Interface, 2015, 12: 292-294

12 Kolinko S, Jogler C, Katzmann E, et al. Single-cell analysis reveals a novel uncultivated magnetotactic bacterium within the candidate division OP3. Environ Microbiol, 2012, 14: 1709-1721

13 Sakaguchi T, Arakaki A, Matsunaga T. Desulfovibrio magneticus sp. nov., a novel sulfate-reducing bacterium that produces intracellular single-domain-sized magnetite particles. Int J Syst Evol Microbiol, 2002, 52: 215-221

14 Morillo V, Abreu F, Araujo A C, et al. Isolation, cultivation and genomic analysis of magnetosome biomineralization genes of a new genus of South-seeking magnetotactic cocci within the Alphaproteobacteria. Front Microbiol, 2014, 5: 72

15 Smith M J, Sheehan P E, Perry L L, et al. Quantifying the magnetic advantage in magnetotaxis. Biophys J, 2006, 91: 1098-1107

16 Faivre D, Schuler D. Magnetotactic bacteria and magnetosomes. Chem Rev, 2008, 108: 4875-4898

17 Komeili A. Molecular mechanisms of compartmentalization and biomineralization in magnetotactic bacteria. FEMS Microbiol Rev, 2012, 36: 232-255

18 Chen C, Ma Q, Jiang W, et al. Phototaxis in the magnetotactic bacterium Magnetospirillum magneticum strain AMB-1 is independent of magnetic fields. Appl Microbiol Biotechnol, 2011, 90: 269-275

19 Matsunaga T, Okamura Y, Fukuda Y, et al. Complete genome sequence of the facultative anaerobic magnetotactic bacterium Magnetospirillum sp. strain AMB-1. DNA Res, 2005, 12: 157-166

20 Alexandre G, Greer-Phillips S, Zhulin I B. Ecological role of energy taxis in microorganisms. FEMS Microbiol Rev, 2004, 28: 113-126

21 Blakemore R P. Magnetotactic bacteria. Annu Rev Microbiol, 1982, 36: 217-238

22 Frankel R B, Bazylinski D A, Johnson M S, et al. Magneto-aerotaxis in marine coccoid bacteria. Biophys J, 1997, 73: 994-1000

23 Leão P, Teixeira L C, Cypriano J, et al. North-seeking magnetotactic Gammaproteobacteria in the Southern Hemisphere. Appl Environ Microbiol, 2016, 82: 5595-5602

24 Lefevre C T, Bennet M, Landau L, et al. Diversity of magneto-aerotactic behaviors and oxygen sensing mechanisms in cultured magnetotactic bacteria. Biophys J, 2014, 107: 527-538

25 Raschdorf O, Forstner Y, Kolinko I, et al. Genetic and ultrastructural analysis reveals the key players and initial steps of bacterial magnetosome membrane biogenesis. PLoS Genet, 2016, 12: e1006101.

26 Tanaka M, Okamura Y, Arakaki A, et al. Origin of magnetosome membrane: proteomic analysis of magnetosome membrane and comparison with cytoplasmic membrane. Proteomics, 2006, 6: 5234-5247

27 Prozorov T, Bazylinski D A, Mallapragada S K, et al. Novel magnetic nanomaterials inspired by magnetotactic bacteria: Topical review. Mater Sci Engineer R: Rep, 2013, 74:133-172

28 Dubbels B L, Dispirito A A, Morton J D, et al. Evidence for a copper-dependent iron transport system in the marine, magnetotactic bacterium strain MV-1. Microbiology, 2004, 150: 2931-2945

29 Grunberg K, Wawer C, Tebo B M, et al. A large gene cluster encoding several magnetosome proteins is conserved in different species of magnetotactic bacteria. Appl Environ Microbiol, 2001, 67: 4573-4582

30 Matsunaga T, Nemoto M, Arakari A, et al. Proteomic analysis of irregular, bullet-shaped magnetosomes in the sulphate-reducing magnetotactic bacterium Desulfovibrio magneticus RS-1. Proteomics, 2009, 9: 3341-3352

31 Okamura Y, Takeyama H, Matsunaga T. Two-dimensional analysis of proteins specific to the bacterial magnetic particle membrane from Magnetospirillum sp. AMB-1. Appl Biochem Biotechnol, 2000, 84-86: 441-446

32 Bazylinski D A, Frankel R B, Jannasch H W. Anaerobic magnetite production by a marine, magnetotactic bacterium. Nature, 1988, 334 : 518-519

33 Guerin W F, Blakemore R P. Redox cycling of iron supports growth and magnetite synthesis by Aquaspirillum magnetotacticum. Appl Environ Microbiol, 1992, 58: 1102-1109

34 Paoletti L C, Blakemore D R P. Iron reduction by Aquaspirillum magnetotacticum. Current Microbiology, 1988, 17: 339-342

35 Richter M, Kube M, Bazylinski D A, et al. Comparative genome analysis of four magnetotactic bacteria reveals a complex set of group-specific genes implicated in magnetosome biomineralization and function. J Bacteriol, 2007, 189: 4899-4910 
36 Ullrich S, Kube M, Schubbe S, et al. A hypervariable 130-kilobase genomic region of Magnetospirillum gryphiswaldense comprises a magnetosome island which undergoes frequent rearrangements during stationary growth. J Bacteriol, 2005, 187: 7176-7184

37 Dobrindt U, Hochhut B, Hentschel U, et al. Genomic islands in pathogenic and environmental microorganisms. Nat Rev Microbiol, 2004, 2: $414-424$

38 Mahillon J, Chandler M. Insertion sequences. Microbiol Mol Biol Rev, 1998, 62: 725-774

39 Mahillon J, Leonard C, Chandler M. IS elements as constituents of bacterial genomes. Res Microbiol, 1999, 150: 675-687

40 Jogler C, Wanner G, Kolinko S, et al. Conservation of proteobacterial magnetosome genes and structures in an uncultivated member of the deep-branching Nitrospira phylum. Proc Natl Acad Sci USA, 2011, 108: 1134-1139

41 Abreu F, Cantao M E, Nicolas M F, et al. Common ancestry of iron oxide- and iron-sulfide-based biomineralization in magnetotactic bacteria. ISME J, 2011, 5: 1634-1640

42 Nakazawa H, Arakaki A, Narita-Yamada S, et al. Whole genome sequence of Desulfovibrio magneticus strain RS-1 revealed common gene clusters in magnetotactic bacteria. Genome Res, 2009, 19: 1801-1808

43 Komeili A, Vali H, Beveridge T J, et al. Magnetosome vesicles are present before magnetite formation, and MamA is required for their activation. Proc Natl Acad Sci USA, 2004, 101: 3839-3844

44 Kolinko S, Richter M, Glockner F O, et al. Single-cell genomics of uncultivated deep-branching magnetotactic bacteria reveals a conserved set of magnetosome genes. Environ Microbiol, 2016, 18: 21-37

45 Lefevre C T, Bazylinski D A. Ecology, diversity, and evolution of magnetotactic bacteria. Microbiol Mol Biol Rev, 2013, 77: 497-526

46 Uebe R, Schuler D. Magnetosome biogenesis in magnetotactic bacteria. Nat Rev Microbiol, 2016, 14: 621-637

47 Arakaki A, Yamagishi A, Fukuyo A, et al. Co-ordinated functions of Mms proteins define the surface structure of cubo-octahedral magnetite crystals in magnetotactic bacteria. Mol Microbiol, 2014, 93: 554-567

48 Kolinko S, Richter M, Glockner F O, et al. Single-cell genomics reveals potential for magnetite and greigite biomineralization in an uncultivated multicellular magnetotactic prokaryote. Environ Microbiol Rep, 2014, 6: 524-531

49 Lin W, Deng A, Wang Z, et al. Genomic insights into the uncultured genus 'Candidatus Magnetobacterium' in the phylum Nitrospirae. ISME J, 2014, 8: 2463-2477

50 Lefevre C T, Trubitsyn D, Abreu F, et al. Monophyletic origin of magnetotaxis and the first magnetosomes. Environ Microbiol, 2013, 15: $2267-2274$

51 Lefevre C T, Menguy N, Abreu F, et al. A cultured greigite-producing magnetotactic bacterium in a novel group of sulfate-reducing bacteria. Science, 2011, 334: 1720-1723

52 Lin W, Bazylinski D A, Xiao T, et al. Life with compass: diversity and biogeography of magnetotactic bacteria. Environ Microbiol, 2014, 16: $2646-2658$

53 Hershey D M, Browne P J, Iavarone A T, et al. Magnetite biomineralization in Magnetospirillum magneticum is regulated by a switch-like behavior in the HtrA protease MamE. J Biol Chem, 2016, 291: 17941-17952

54 Yamamoto D, Taoka A, Uchihashi T, et al. Visualization and structural analysis of the bacterial magnetic organelle magnetosome using atomic force microscopy. Proc Natl Acad Sci USA, 2010, 107: 9382-9387

55 Shiran B Z, René U, Geula D, et al. Disease-homologous mutation in the cation diffusion facilitator protein MamM causes single-domain structural loss and signifies its importance. Scientific Reports, 2016, 6: 31933

56 Uebe R, Junge K, Henn V, et al. The cation diffusion facilitator proteins MamB and MamM of Magnetospirillum gryphiswaldense have distinct and complex functions, and are involved in magnetite biomineralization and magnetosome membrane assembly. Mol Microbiol, 2011, 82: 818-835

57 Zeytuni N, Uebe R, Maes M, et al. Bacterial magnetosome biomineralization--a novel platform to study molecular mechanisms of human CDF-related Type-II diabetes. PLoS One, 2014, 9: e97154

58 Zeytuni N, Uebe R, Maes M, et al. Cation diffusion facilitators transport initiation and regulation is mediated by cation induced conformational changes of the cytoplasmic domain. PLoS One, 2014, 9: e92141

59 Faivre D, Bottger L H, Matzanke B F, et al. Intracellular magnetite biomineralization in bacteria proceeds by a distinct pathway involving membrane-bound ferritin and an iron(II) species. Angew Chem Int Ed Engl, 2007, 46: 8495-8499

60 Calugay R J, Takeyama H, Mukoyama D, et al. Catechol siderophore excretion by magnetotactic bacterium Magnetospirillum magneticum AMB-1. J Biosci Bioeng, 2006, 101: 445-447

61 Uebe R, Voigt B, Schweder T, et al. Deletion of a fur-like gene affects iron homeostasis and magnetosome formation in Magnetospirillum gryphiswaldense. J Bacteriol, 2010, 192: 4192-4204 
62 Wang Q, Wang M, Wang X, et al. Iron response regulator protein IrrB in Magnetospirillum gryphiswaldense MSR-1 helps control the iron/oxygen balance, oxidative stress tolerance and magnetosome formation. Appl Environ Microbiol, 2015, 81: 8044-8053

63 Qi L, Li J, Zhang W, et al. Fur in Magnetospirillum gryphiswaldense influences magnetosomes formation and directly regulates the genes involved in iron and oxygen metabolism. PLoS One, 2012, 7: e29572

64 Raschdorf O, Muller F D, Posfai M, et al. The magnetosome proteins MamX, MamZ and MamH are involved in redox control of magnetite biomineralization in Magnetospirillum gryphiswaldense. Mol Microbiol, 2013, 89: 872-886

65 Siponen M I, Legrand P, Widdrat M, et al. Structural insight into magnetochrome-mediated magnetite biomineralization. Nature, 2013 , 502: 681-684

66 Murat D, Quinlan A, Vali H, et al. Comprehensive genetic dissection of the magnetosome gene island reveals the step-wise assembly of a prokaryotic organelle. Proc Natl Acad Sci USA, 2010, 107: 5593-5598

67 Quinlan A, Murat D, Vali H, et al. The HtrA/DegP family protease MamE is a bifunctional protein with roles in magnetosome protein localization and magnetite biomineralization. Mol Microbiol, 2011, 80: 1075-1087

68 Siponen M I, Adryanczyk G, Ginet N, et al. Magnetochrome: a c-type cytochrome domain specific to magnetotatic bacteria. Biochem Soc Trans, 2012, 40: 1319-1323

69 Kashyap S, Woehl T J, Liu X, et al. Nucleation of iron oxide nanoparticles mediated by Mms6 protein in situ. ACS Nano, 2014, 8: 9097-9106

70 Jones S R, Wilson T D, Brown M E, et al. Genetic and biochemical investigations of the role of MamP in redox control of iron biomineralization in Magnetospirillum magneticum. Proc Natl Acad Sci USA, 2015, 112: 3904-3909

71 Yang W, Li R, Peng T, et al. MamO and mamE genes are essential for magnetosome crystal biomineralization in Magnetospirillum gryphiswaldense MSR-1. Res Microbiol, 2010, 161: 701-705

72 Hershey D M, Ren X, Melnyk R A, et al. MamO is a repurposed serine protease that promotes magnetite biomineralization through direct transition metal binding in magnetotactic bacteria. PLoS Biol, 2016, 14: e1002402

73 Arakaki A, Webb J, Matsunaga T. A novel protein tightly bound to bacterial magnetic particles in Magnetospirillum magneticum strain AMB-1. J Biol Chem, 2003, 278: 8745-8750

74 Nudelman H, Valverde-Tercedor C, Kolusheva S, et al. Structure-function studies of the magnetite-biomineralizing magnetosome-associated protein MamC. J Struct Biol, 2016, 194: 244-252

75 Tanaka M, Mazuyama E, Arakaki A, et al. MMS6 protein regulates crystal morphology during nano-sized magnetite biomineralization in vivo. J Biol Chem, 2011, 286: 6386-6392

76 Faivre D, Godec T U. From bacteria to mollusks: the principles underlying the biomineralization of iron oxide materials. Angew Chem Int Ed Engl, 2015, 54: 4728-4747

77 Klumpp S, Faivre D. Interplay of magnetic interactions and active movements in the formation of magnetosome chains. PLoS One, 2012, 7: e 33562

78 Scheffel A, Gruska M, Faivre D, et al. An acidic protein aligns magnetosomes along a filamentous structure in magnetotactic bacteria. Nature, 2006, 440: 110-114

79 Scheffel A, Schuler D. The acidic repetitive domain of the Magnetospirillum gryphiswaldense MamJ protein displays hypervariability but is not required for magnetosome chain assembly. J Bacteriol, 2007, 189: 6437-6446

80 Pan W, Xie C, Lv J. Screening for the interacting partners of the proteins MamK \& MamJ by two-hybrid genomic DNA library of Magnetospirillum magneticum AMB-1. Curr Microbiol, 2012, 64: 515-523

81 Draper O, Byrne M E, Li Z, et al. MamK, a bacterial actin, forms dynamic filaments in vivo that are regulated by the acidic proteins MamJ and LimJ. Mol Microbiol, 2011, 82: 342-354

82 Rioux J B, Philippe N, Pereira S, et al. A second actin-like MamK protein in Magnetospirillum magneticum AMB-1 encoded outside the genomic magnetosome island. PLoS One, 2010, 5: e9151

83 Schultheiss D, Schuler D. Development of a genetic system for Magnetospirillum gryphiswaldense. Arch Microbiol, 2003, 179: 89-94

84 Deng Q, Liu Y, Wang S. Research progress of magnetosomes used as natural magnetic targeting drug-nanocarriers. Chin J, 2014, 59 : 945

85 Wang H, Li Z, Jia R, et al. RecET direct cloning and Redalphabeta recombineering of biosynthetic gene clusters, large operons or single genes for heterologous expression. Nat Protoc, 2016, 11: 1175-1190

$86 \mathrm{Fu} \mathrm{J}$, Bian X, Hu S, et al. Full-length RecE enhances linear-linear homologous recombination and facilitates direct cloning for bioprospecting. Nat Biotechnol, 2012, 30: 440-446

87 Kolinko I, Lohsse A, Borg S, et al. Biosynthesis of magnetic nanostructures in a foreign organism by transfer of bacterial magnetosome 
gene clusters. Nat Nanotechnol, 2014, 9: 193-197

88 Lohsse A, Kolinko I, Raschdorf O, et al. Overproduction of magnetosomes by genomic amplification of biosynthesis-related gene clusters in a magnetotactic bacterium. Appl Environ Microbiol, 2016, 82: 3032-3041

89 Lang C, Schuler D. Expression of green fluorescent protein fused to magnetosome proteins in microaerophilic magnetotactic bacteria. Appl Environ Microbiol, 2008, 74: 4944-4953

90 Borg S, Hofmann J, Pollithy A, et al. New vectors for chromosomal integration enable high-level constitutive or inducible magnetosome expression of fusion proteins in Magnetospirillum gryphiswaldense. Appl Environ Microbiol, 2014, 80: 2609-2616

91 Ginet N, Pardoux R, Adryanczyk G, et al. Single-step production of a recyclable nanobiocatalyst for organophosphate pesticides biodegradation using functionalized bacterial magnetosomes. PLoS One, 2011, 6: e21442

92 Yoshino T, Matsunaga T. Efficient and stable display of functional proteins on bacterial magnetic particles using mms 13 as a novel anchor molecule. Appl Environ Microbiol, 2006, 72: 465-471

93 Hatakeyama K, Tanaka T, Sawaguchi M, et al. Microfluidic device using chemiluminescence and a DNA-arrayed thin film transistor photosensor for single nucleotide polymorphism genotyping of PCR amplicons from whole blood. Lab on A Chip, 2009, 9: 1052-1058

94 Howarth M, Takao K, Hayashi Y, et al. Targeting quantum dots to surface proteins in living cells with biotin ligase. Proc Natl Acad Sci USA, 2005, 102: 7583-7588

95 Larsson C, Rodahl M, Hook F. Characterization of DNA immobilization and subsequent hybridization on a 2D arrangement of streptavidin on a biotin-modified lipid bilayer supported on SiO2. Anal Chem, 2003, 75: 5080-5087

96 Matsunaga T, Maeda Y, Yoshino T, et al. Fully automated immunoassay for detection of prostate-specific antigen using nano-magnetic beads and micro-polystyrene bead composites, 'Beads on Beads'. Anal Chim Acta, 2007, 597: 331-339

97 Liao S, Seeman N C. Translation of DNA signals into polymer assembly instructions. Science, 2004, 306: 2072-2074

98 Sato R, Takeyama H, Tanaka T, et al. Development of high-performance and rapid immunoassay for model food allergen lysozyme using antibody-conjugated bacterial magenetic particles and fully automated system. Appl Biochem Biotechnol, 2001, 91-93: 109

99 Matsunaga T S R, Kamiya S, et al. Chemiluminescence enzyme immunoassay using ProteinA-bacterial magnetite complex. J Magn Magn Mater, 1999, 194: 126-131

100 Klem M T, Young M, Douglas T. Biomimetic magnetic nanoparticles. Mater Today, 2005, 8: 28-37

101 George A, Ravindran S. Protein templates in hard tissue engineering. Nano Today, 2010, 5: 254-266

102 Luckarift H R, Dickerson M B, Sandhage K H, et al. Rapid, room-temperature synthesis of antibacterial bionanocomposites of lysozyme with amorphous silica or titania. Small, 2006, 2: 640-643

103 An X, Cao C, Zhu H. Bio-inspired fabrication of $\mathrm{ZnO}$ nanorod arrays and their optical and photoresponse properties. J Cryst Growth, 2007, 308: 340-347

104 Ditsch A, Laibinis P E, Wang D I, et al. Controlled clustering and enhanced stability of polymer-coated magnetic nanoparticles. Langmuir, 2005, 21: 6006-6018

105 Grunwald I, Rischka K, Kast S M, et al. Mimicking biopolymers on a molecular scale: nano(bio)technology based on engineered proteins. Philos Trans A Math Phys Eng Sci, 2009, 367: 1727-1747

106 Douglas T, Stark V T. Nanophase cobalt oxyhydroxide mineral synthesized within the protein cage of ferritin. Inorg Chem, 2000, 39 : $1828-1830$

107 Meldrum F C, Heywood B R, Mann S. Magnetoferritin: in vitro synthesis of a novel magnetic protein. Science, 1992, 257: 522-523

108 Politi Y L-K Y, Raz S, et al. Structural characterization of the transient amorphous calcium carbonate precursor phase in sea urchin embryos. Adv Funct Mater, 2006, 16: 1289-1298

109 James J. De Yoreo P G V. Principles of crystal nucleation and growth. Rev Mineral Geochem, 2003, 54: 57-93

110 Fortin D, Langley S. Formation and occurrence of biogenic iron-rich minerals. Earth-Sci Rev, 2005, 72: 1-19

111 De Yoreo J J, Dove P M. Materials science. Shaping crystals with biomolecules. Science, 2004, 306: 1301-1302

112 Dey A, Bomans P H, Muller F A, et al. The role of prenucleation clusters in surface-induced calcium phosphate crystallization. Nat Mater, 2010, 9: 1010-1014

113 Nudelman F, Bomans P H H, George A, et al. The role of the amorphous phase on the biomimetic mineralization of collagen. Faraday Discuss, 2012, 159: 357

114 Amemiya Y, Arakaki A, Staniland S S, et al. Controlled formation of magnetite crystal by partial oxidation of ferrous hydroxide in the presence of recombinant magnetotactic bacterial protein Mms6. Biomaterials, 2007, 28: 5381-5389

115 Baumgartner J, Bertinetti L, Widdrat M, et al. Formation of magnetite nanoparticles at low temperature: from superparamagnetic to 
stable single domain particles. PLoS One, 2013, 8: e57070

116 Baumgartner J, Dey A, Bomans P H, et al. Nucleation and growth of magnetite from solution. Nat Mater, 2013, 12: 310-314

117 Daniela F, Clemens D, Gunter A, et al. Ultrasmall superparamagnetic iron oxide (USPIO)-based liposomes as magnetic resonance imaging probes. Int J Nanomedicine, 2012, 7: 2349-2359

118 Bakandritsos A, Bouropoulos N, Koutoulogenis A, et al. Synthesis and characterization of iron oxide nanoparticles encapsulated in lipid membranes. J Biomed Nanotechnol, 2008, 4: 313-318

119 Gilmore K, Idzerda Y U, Klem M T, et al. Surface contribution to the anisotropy energy of spherical magnetite particles. J Appl Phys, 2005, 97: 10B301-10B301-3

120 Shenton W, Mann S, Cölfen H, et al. Synthesis of nanophase iron oxide in lumazine synthase capsids. Angew Chem Int Ed, 2001, 113: 456-459

121 Staniland S, Williams W, Telling N, et al. Controlled cobalt doping of magnetosomes in vivo. Nat Nanotechnol, 2008, 3: 158-162

122 李金华, Nicolas Menguy, Philippe Sainctavit, 等. 磁小体磁铁矿晶格中钴的掺杂及其磁学效应. 中国地球科学联合学术年会, 2014.

123 Chen Q, Xu L, Liang C, et al. Photothermal therapy with immune-adjuvant nanoparticles together with checkpoint blockade for effective cancer immunotherapy. Nat Comm, 2016, 7: 13193

124 Mahmoudi M, Tachibana A, Goldstone A B, et al. Novel MRI contrast agent from magnetotactic bacteria enables in vivo tracking of iPSC-derived Cardiomyocytes. Sci Rep, 2016, 6: 26960

125 Goldhawk D E, Rohani R, Sengupta A, et al. Using the magnetosome to model effective gene-based contrast for magnetic resonance imaging. WIREs Nanomed Nanobiotechnol, 2012, 4: 378-388

126 Xie J, Chen K, Chen X. Production, Modification and bio-applications of magnetic nanoparticles gestated by magnetotactic bacteria. Nano Res, 2009, 2: 261-278

127 Ceyhan B, Alhorn P, Lang C, et al. Semisynthetic biogenic magnetosome nanoparticles for the detection of proteins and nucleic acids. Small, 2006, 2: 1251-1255

128 Matsunaga T, Maruyama K, Takeyama H, et al. High-throughput SNP detection using nano-scale engineered biomagnetite. Biosens Bioelectron, 2007, 22: 2315-2321

129 Sun J B, Duan J H, Dai S L, et al. In vitro and in vivo antitumor effects of doxorubicin loaded with bacterial magnetosomes (DBMs) on H22 cells: the magnetic bio-nanoparticles as drug carriers. Cancer Lett, 2007, 258: 109-117

130 Sun J B, Duan J H, Dai S L, et al. Preparation and anti-tumor efficiency evaluation of doxorubicin-loaded bacterial magnetosomes: magnetic nanoparticles as drug carriers isolated from Magnetospirillum gryphiswaldense. Biotechnol Bioeng, 2008, 101: 1313-1320

131 Sun X, Liu Z, Welsher K, et al. Nano-graphene oxide for cellular imaging and drug delivery. Nano Res, 2008, 1: 203-212

132 Sun J B, Wang Z L, Duan J H, et al. Targeted distribution of bacterial magnetosomes isolated from Magnetospirillum gryphiswaldense MSR-1 in healthy Sprague-Dawley rats. J Nanosci Nanotechnol, 2009, 9: 1881-1885

133 Tang Y S, Wang D, Zhou C, et al. Bacterial magnetic particles as a novel and efficient gene vaccine delivery system. Gene Ther, 2012, 19: $1187-1195$

134 Li A, Zhang H, Zhang X, et al. Rapid separation and immunoassay for low levels of Salmonella in foods using magnetosome-antibody complex and real-time fluorescence quantitative PCR. J Separ Sci, 2010, 33: 3437-3443

135 Lisy M R, Hartung A, Lang C, et al. Fluorescent bacterial magnetic nanoparticles as bimodal contrast agents. Invest Radiol, 2007, 42: $235-241$

136 Felfoul O, Mohammadi M, Taherkhani S, et al. Magneto-aerotactic bacteria deliver drug-containing nanoliposomes to tumour hypoxic regions. Nat Nanotechnol, 2016, 11: 941-947

137 Zanganeh S, Hutter G, Spitler R, et al. Iron oxide nanoparticles inhibit tumour growth by inducing pro-inflammatory macrophage polarization in tumour tissues. Nat Nanotechnol, 2016, 11: 986-994

138 Din M O, Danino T, Prindle A, et al. Synchronized cycles of bacterial lysis for in vivo delivery. Nature, 2016, 536: 81-85

139 Forbes N S. Engineering the perfect (bacterial) cancer therapy. Nat Rev Cancer, 2010, 10: 785-794

140 Chen C, Wang S, Li L, et al. Bacterial magnetic nanoparticles for photothermal therapy of cancer under the guidance of MRI. Biomaterials, 2016, 104: 352 


\title{
Biosynthesis and application of magnetosomes in tumor-targeting therapy
}

\author{
ZHONG Lin, LI XiaoChen, FU Jun, ZHANG YouMing, Li AiYing \\ Shandong University-Helmholtz Institute of Biotechnology, The State Key Laboratory of Microbial Technology, The School of Life Sciences, \\ Shandong University, Jinan 250100, China
}

\begin{abstract}
Magnetosomes are nano-sized natural crystalline particles that are biomineralized by magnetotactic bacteria. They have attracted much attention because of their superior nano-magnetic properties, unprecedented biocompatibility, and genetic maneuverability endowed by magnetotactic bacteria. Magnetosomes can potentially be used in many fields. In the biomedicine field, in addition to their application in tumor-targeting magnetic hyperthermia, the capability of magnetosomes to deliver tumor-targeting drugs and their possible involvement in the regulation of the tumor microenvironment have become popular research topics in recent years. Moreover, technological developments in DNA recombination techniques resolved the bottleneck due to the low-yield magnetosome production by unculturable magnetotactic bacteria. This article is mainly focused on the biosynthesis of magnetosomes and related research progress in recent years and the prospects for their application in the future.
\end{abstract}

Magnetosome, Magnetotactic bacteria, biosynthesis, genetic engineering technology, tumor-targeting therapy doi: 10.1360/N052017-00066 